\title{
University Students' Perspective of Sexual Harassment: A Case Study of the University of Zambia
}

\author{
Menon $\mathbf{A}^{1}$, Shilalukey Ngoma M.P ${ }^{2}$, Siziya $\mathrm{S}^{3}$, Ndubani ${ }^{4}$, Musepa $\mathbf{M}^{5}$, Malungo $\mathbf{J}^{6}$, \\ Munalula $\mathbf{B}^{7}$, Mwela $\mathbf{M}^{8}$, Serpell $\mathbf{R}^{9}$
}

1. Department of Psychology, Chairperson of the University Committee on HIV and AIDS, University of Zambia

2. Department of Paediatrics and Child Health, University of Zambia, School of Medicine 3. Department of Community Medicine, University of Zambia, School of Medicine

4. Directorate of Research and Graduate Studies, University of Zambia

5. Public Relations Department, University of Zambia

6. Department of Social Development Studies, University of Zambia

7. Department of Physiological Sciences, University of Zambia, School of Medicine

8. University Response to HIV and AIDS Program, University of Zambia

9. Department of Psychology, University of Zambia

\begin{abstract}
Objectives: To determine if sexual harassment was a problem at the University of Zambia (UNZA); to explore UNZA student's perception on the nature of sexual harassment; and determine student's knowledge and understanding about sexual harassment.
\end{abstract}

Design: A cross-sectional study across UNZA.

Main outcomes: Occurrence of sexual harassment at UNZA; knowledge, perception and understanding of sexual harassment.

Measure: A self-administered questionnaire was developed for the purpose of the study and piloted. The questionnaire included items on perceptions and understanding of sexual harassment; the nature of

\footnotetext{
Corresponding Author:

Anitha Menon

Department of Psychology, Chairperson of the University Committee on HIV and AIDS, University of Zambia

P.O. Box 38301, Lusaka, Zambia.

E mail: anithamenon667@hotmail.com
}

the environment at UNZA; frequency of the occurrence of sexual harassment; direct experiences and observations of sexual harassment; and formal and informal reporting of sexual harassment.

Results: This study found that sexual harassment was a problem at UNZA and female students were more likely to be affected. There was no gender difference on the knowledge about sexual harassment $(p=0.27)$ but there was a significant gender difference in the perception of sexual harassment occurring at UNZA $\left(\mathrm{X}^{2}=86.51, \mathrm{df}=1\right.$, $\mathrm{p}<0.001$ ), there were significantly more female students who perceived a lot of sexual harassment to be occurring at UNZA. More female students also perceived that students were likely to harass other students $(\mathrm{p}<0.01)$ and students were likely to harass lecturers $(\mathrm{p}<0.001)$.

Conclusion: The problem of sexual harassment at UNZA should not be underestimated, among our recommendation is to formulate a policy on sexual harassment at UNZA. 


\section{INTRODUCTIONAND BACKGROUND}

Sexual harassment is the most common form of sexual victimisation and was also described as a form of social control by men to 'keep women in their places' ${ }^{1}$. In spite of the importance of this topic in the social context that we live in, it is interesting that for several years there was silence on the issue of sexual harassment occurring in institutions of higher education throughout the world ${ }^{2}$. In 1978, the project on Status and Education of Women of the Association of American College referred to sexual harassment as a 'hidden issue' to highlight the issue and the silence that surrounded sexual harassment at both individual and organizational levels ${ }^{2}$. However, until recently, there have been few researches carried out in the African region on sexual harassment in tertiary institutions of learning ${ }^{3}$.

Although the definitions of sexual harassment varies in different academic setting, most of the campus studies define sexual harassment behaviors in terms of one or both of two major categories: gender harassment (sexist remarks and behaviors) and variously defined levels of sexual advances, bribery and $\operatorname{coercion}^{4,5}$. This study used the definition of sexual harassment from the University of Zambia (UNZA) HIV and AIDS Policy (2006) ${ }^{6}$ : Sexual harassment is defined by the UNZA HIV and AIDS policy (2006) as "unwelcome sexual advances, requests for sexual favors, and other verbal or physical conduct of a sexual nature, when submission to or rejection of this conduct explicitly or implicitly affects a person's employment or education, unreasonably interferes with a person's work or educational performance, or creates an intimidating, hostile or offensive working or learning environment.

The definition of sexual harassment in UNZA HIV and AIDS policy (2006) recognises that sexual harassment may involve individuals of either sex, and be between members of the same or opposite sex and typically involves a person in a position of power as the initiator. However, it may also occur in a variety of ways, e.g. harassment of student by student, staff member by staff member, staff member by student or student by staff member, where there is an element of threat or coercion in the behavior. Harassment can occur anywhere on campus, including the classroom, the workplace, or a residence hall ${ }^{\text {? }}$. Quid Pro Quo is a Latin phrase meaning this for that or something for something, exchange between parties where one is asked to provide sexual favors in return for something else. In academia, sexual harassment is likely to take this form; examples include provision of sexual favors in exchange for grades, inclusion in activities and scholarships. Sexual harassment can be said to occur when any such behaviour creates an intimidating, hostile or offensive environment for work and study. The defining features of sexual harassment are that the behaviour is offensive to and unwanted by the recipient.

The issue of sexual harassment is of serious concern since it is estimated that over $50 \%$ of all women have experienced sexual harassment in the workplace and $20-30 \%$ of all college women have been sexually harassed ${ }^{7}$. It is of concern since sexual harassment interferes with human rights as the victims experience stressful physical and psychological effects which may in turn prevent them from achieving their rightful place in employment and education ${ }^{2}$.

The occurrences of sexual harassment have been reported at both workplaces and in education institutions. Universities are complex in terms of structure as they involve characteristics of work environment and that of education institutions. Some of the consequences of sexual harassment at workplace included were disturbed mental health function, decline in job performance, and headache ${ }^{8}$. Earlier surveys that focused on women at the work place and found between $50 \%$ and $92 \%$ of the respondents had experienced some form of sexual harassment ${ }^{8}$.

Many research studies on sexual harassment have also be carried in higher education institution ${ }^{5,9,10,11}$. The results of these surveys are somewhat difficult to compare because the definitions of sexual harassment, sampling procedures, populations studied, and research methodologies often vary from one study to another. Taken as a whole, however, these studies clearly indicate that sexual harassment is a serious and widespread problem for 
students, faculty and staff at colleges and universities today. In general, female students were shown to be harassed significantly more than male students ${ }^{12}$. Prevalence rates among graduate female students appeared to be either comparable to or higher than sexual harassment experiences among undergraduate female students. Both other studies reported that sexual harassment among graduate female students was considerably higher than for undergraduates ${ }^{5}$. Further, it was found that the longer the students stayed on campus, the higher was the prevalence rates ${ }^{4}$.

We did not find any specific studies on sexual harassment carried out in Universities in Zambia but since 1990s there have been many important studies on the nature and practice of sexual harassment in the African region. The African Gender Institute carried out a project from mid 2005 to $2006^{13}$ to explore the effectiveness of official campus policies on sexual harassment in the complex climates of diversity, discrimination and opportunity that characterize contemporary higher education institutions. The three campuses involved in this project were the University of Western Cape, University of Botswana and University of Stellenbosch. This project came up with a number of important findings. The hierarchical nature of the Universities together with the patriarchal cultures of leadership was found to create various zones of vulnerability to sexual harassment especially in junior students. The research also found transactional sex which included transaction for higher grades, academic opportunities and financial resources. Many male students and male staff also considered themselves to have been harassed by women. Another theme of concern that emerged was the difficulty of the survivors of sexual harassment to voice their experiences due to pain, humiliation, anger and confusion.

\section{Problem Statement}

Previous research studies have reported sexual harassment to be commonly occurring in workplaces and educational institutions. Although the code of conduct (UNZA 2006) considered sexual harassment as an act requiring disciplinary action, there is no policy or legislation on sexual harassment at the University of Zambia. Given the grave nature of sexual harassment, the study was conducted with an assumption that sexual harassment is contrary to any University's values and moral standards, which recognize the dignity and worth of each person. Sexual harassment, if existed at UNZA, would subvert the mission of the University and offend the integrity of the University community. Therefore, it becomes important to determine if sexual harassment exists at UNZA, this is the first study on this topic carried out at UNZA. This is a part of a larger study carried out on the whole UNZA community made up of students, academic staff and non-academic staff.

\section{Study objectives}

- To determine if sexual harassment was a problem at UNZA

- To explore UNZA students knowledge and understanding about sexual harassment

- To explore the perception UNZA students on the nature of sexual harassment existing on campus

\section{METHODOLOGY}

\section{Participants}

The participants were students from the 9 schools across UNZA. During the period of study (academic year 2006-2007) UNZA had 8010 full-time students and 1,991 on distance study programs. We targeted $25 \%$ of the full-time student population at UNZA. The total number of all the students enrolled by year of study was used as the sampling frame. The participants were selected using a stratified sequential sample, using schools, departments and sex as strata. Then, systematic sampling was applied using probability proportion to size (PPS). This entailed that more participants were selected from larger classes and schools.

\section{Measure}

A self-administered questionnaire was developed for the purpose of the study and piloted. The questionnaire included items on perceptions and understanding of sexual harassment; the nature of the environment at UNZA; frequency of the occurrence of sexual harassment; direct experiences and observations of sexual harassment; and formal and informal reporting of sexual harassment. For the purpose of this study, reporting of sexual harassment was not included in the analysis. The students were given a rating to choose from for each of the items, the scale for rating varied from item to item. The 
questionnaire was pilot tested with students who were subsequently not included in the present study. To ensure understanding of the concept, the definition of sexual harassment was included on the cover page of the questionnaire.

\section{Procedure}

The data were collected by trained research assistants, the participants were met in classrooms, with consent from their lecturers. The research assistant explained the purpose of the study to the participants and what would be expected if they consented to participate. The questionnaires were then distributed to students who consented to take part in the study. Upon completion, most of the students returned the questionnaires in a sealed envelope.

\section{Ethical consideration}

The study was conducted after obtaining permission from UNZA administration. Approval was obtained from Research Ethics Committee at the University of Zambia prior to the commencement of the research. An informed verbal consent was obtained from the participants prior to participation in the research. The data were coded to remove any identification of participants.

\section{Data Management and Processing}

Data were entered through EPI-data software package and verified and processed using EPI-Info software package. Simple range and skip errors were corrected at the data entry point while data verification and cleaning were carried out immediately after data entry. Statistical analysis was carried SPSS version 15 for windows. Data were analysed to explore gender differences in the perception of sexual harassment.

\section{RESULTS}

\section{Response rate}

Of the 2003 students targeted, we received the questionnaire back from 855 students, giving us a response rate of $44.2 \%$.

\section{Background characteristics of the participants}

A total of 885 students took part in this study, 401(45.3\%) were male students, while 422 (47.7\%) were female students. Most of the students (55.4\%) were in the age range of 20-24 years. Sixty-two students did not indicate their sex in the questionnaire.

\section{Perceived knowledge about sexual harassments}

Majority of the participants $(71.5 \%)$ reported that they had knowledge about sexual harassment, while $5.8 \%$ indicated that they did not have knowledge about sexual harassment (Table 2). A small percentage $(3 \%)$ did not indicate their answer and $15.9 \%$ indicated that they were not sure about their knowledge about sexual harassment. There was no gender difference on the knowledge about sexual harassment $(p=0.27)$.

Table 1. Participants perceived knowledge about sexual harassment

\begin{tabular}{|c|c|c|c|c|c|c|c|c|}
\hline \multirow{3}{*}{ Students } & \multicolumn{8}{|c|}{$\begin{array}{l}\text { Response about knowledge of sexual } \\
\text { harassment }\end{array}$} \\
\hline & \multicolumn{2}{|l|}{ Yes } & \multicolumn{2}{|c|}{ No } & \multicolumn{2}{|c|}{ Not sure } & \multicolumn{2}{|c|}{$\begin{array}{l}\text { No } \\
\text { response }\end{array}$} \\
\hline & $\mathrm{n}$ & $\%$ & $\mathrm{n}$ & $\%$ & $\mathrm{n}$ & $\%$ & $\mathrm{n}$ & $\%$ \\
\hline Males & 306 & 76.3 & 11 & 2.7 & 79 & 19.7 & 5 & 1.2 \\
\hline Females & 305 & 72.3 & 39 & 9.2 & 57 & 13.5 & 21 & 5.0 \\
\hline TOTAL & 611 & 71.5 & 50 & 5.8 & 136 & 15.9 & 26 & 3 \\
\hline
\end{tabular}

\section{Acts Considered To Be Sexual Harassment}

In the questionnaire were acts considered as sexual harassment in the UNZA HIV and AIDS policy (2006) and the participants indicated if they considered these acts to be sexual harassment. The responses of the participants are displayed in Table 2.There were some gender differences in the correct understanding of sexual harassment. For some items, females had a better understanding (persistent, unwanted sexual or romantic attention; subtle or overt pressure for sexual favours), while for others male students had a better understanding (explicit statements, jokes, anecdotes or remarks of sexual nature; exposure to sexually suggestive visual displays such as photographs). 
Table 2. Correct Understanding of Sexual Harassment

\begin{tabular}{|l|l|l|l|}
\hline \multirow{2}{*}{$\begin{array}{l}\text { Understanding of sexual } \\
\text { harassment }\end{array}$} & \multicolumn{2}{|l|}{$\begin{array}{l}\text { Percentage of students with correct } \\
\text { understanding } \\
\text { (N= 885) }\end{array}$} & $\begin{array}{l}\text { Gender difference } \\
\text { (p value) }\end{array}$ \\
\cline { 2 - 3 } & $\begin{array}{l}\text { Male } \\
\text { n (\%) }\end{array}$ & $\begin{array}{l}\text { Female } \\
\text { n (\%) }\end{array}$ & \\
\hline $\begin{array}{l}\text { Explicit or implicit } \\
\text { propositions to engage in } \\
\text { sexual activity }\end{array}$ & $191(47.6 \%)$ & $206(48.8)$ & 0.73 \\
\hline $\begin{array}{l}\text { Explicit statements, jokes, } \\
\text { anecdotes or remarks of } \\
\text { sexual nature }\end{array}$ & $177(44.1)$ & $149(35.3)$ & $0.01^{*}$ \\
\hline $\begin{array}{l}\text { Deliberate, repeated } \\
\text { humiliation or intimidation } \\
\text { based upon the sex }\end{array}$ & $219(54.6)$ & $220(52.1)$ & 0.78 \\
\hline $\begin{array}{l}\text { Remarks about sexual } \\
\text { activities or speculations } \\
\text { about sexual experience }\end{array}$ & $77(19.2)$ & $88(20.9)$ & 0.55 \\
\hline $\begin{array}{l}\text { Exposure to sexually } \\
\text { suggestive visual displays } \\
\text { such as photographs }\end{array}$ & $129(32.2)$ & $104(24.6 \%)$ & $0.02^{* *}$ \\
\hline $\begin{array}{l}\text { Persistent, unwanted sexual } \\
\text { or romantic attention }\end{array}$ & $159(39.7)$ & $327(77.4)$ & $0 *$ \\
\hline $\begin{array}{l}\text { Deliberate phys } \\
\text { interference with or } \\
\text { restrictions of individuals }\end{array}$ & $92(22.9)$ & $115(36.7)$ & 0.16 \\
\hline $\begin{array}{l}\text { Subtle or overt pressure for } \\
\text { sexual favours }\end{array}$ & $255(63.6)$ & $298(70.6)$ & $0.03^{*}$ \\
\hline $\begin{array}{l}\text { Intentional touching or } \\
\text { physical assault }\end{array}$ & $264(65.8)$ & $273(64.7)$ & 0.73 \\
\hline & & \\
\hline
\end{tabular}

* significant at 0.01 level

** significant at 0.05 level

\section{Perception of sexual harassment occurring at UNZA}

Respondents were asked about how much sexual harassment they thought there is at UNZA, and results are presented in Table 3. There was a significant gender difference in the perception of sexual harassment occurring at UNZA $\left(\mathrm{X}^{2}=86.51\right.$, $\mathrm{df}=1, \mathrm{p}<0.001)$, there were significantly more number of female students who perceive a lot of sexual harassment to be occurring at UNZA.

Furthermore the participants were asked about their perception about the categories of UNZA community who were more likely to be involved in sexual harassment. Significantly more female students perceived that students were likely to harass other students $(\mathrm{p}<0.01)$ and students were likely to harass lecturers $(p<0.001)$. However, significantly more male students perceived that lecturers and non-academic staff were likely to harass students $(\mathrm{p}<0.001)$.

The participants were also asked about the perception of the gender that is more vulnerable to sexual harassment; results revealed that majority $(71.8 \%)$ of the respondents felt that females were more likely to be sexually harassed than males. On the other hand when asked about who was likely to harass another person, $72.7 \%$ of the respondents said that males were more likely to harass females compared to only $2.1 \%$ who said females were more likely to sexually harass males.

\section{Existence of Sexual Harassment at UNZA}

More male students were 'never worried' about being sexually harassed at UNZA, whereas more female students reported about being 'occasionally' worried about being sexually harassed at UNZA $\left(\mathrm{X}^{2}\right.$ $=271.5, \mathrm{df}=2, \mathrm{p}<0.01)$. Of the students who reported to having been sexually harassed, significantly more female students reported to have been harassed by male students $\left(X^{2}=196.2, \mathrm{df}=2\right.$, $\mathrm{p}<0.01)$; male academic member of $\operatorname{staff}\left(\mathrm{X}^{2}=88.8\right.$, $\mathrm{df}=2, \mathrm{p}<0.001)$; and male non-academic members of $\operatorname{staff}\left(X^{2}=21.3, \mathrm{df}=2, \mathrm{p}<0.001\right)$.

\section{DISCUSSION}

This study was conducted with an objective of determining if sexual harassment was a problem at UNZA and exploring the knowledge, understanding and perception of UNZA students about the nature of sexual harassment at UNZA.

Majority of students perceived that they had knowledge about sexual harassment and there was no significant gender difference in this response, although a very small percentage, more female students reported not knowing what sexual harassment was. It may be argued that correct knowledge of sexual harassment is more important as this leads to recognition of acts of sexual harassment that may be reported, the correct knowledge in the study was determined by the acts considered to be sexual harassment in the UNZA HIV and AIDS Policy (2006). It was interesting to observe that a majority of the participants, considered deliberate, repeated humiliation or intimidation based upon the sex; persistent, unwanted sexual or romantic attention; persistent, unwanted sexual or romantic attention; subtle or overt pressure for sexual favours; and intentional touching or physical assault, to be acts of sexual harassment. Whereas only a small percentage of the respondents considered 
remarks about sexual activities or speculations about sexual experience and deliberate physical interference with or restrictions of individuals, to be acts of sexual harassment. One of the earlier studies ${ }^{14}$ observed that college students may not know what sexual harassment is if they have not been sensitized, this may be the case with our sample as there have been no programs to sensitise the UNZA community on sexual harassment.

We also found gender difference in the correct knowledge about sexual harassment, more female students correctly perceived overt acts of sexual nature and subtle or overt pressure for sexual favours as acts of sexual harassment, whereas more male students correctly perceived explicit statements, jokes, remarks of sexual nature and exposure to suggestive displays of sexual nature to be sexual harassment. This finding can be viewed in light of the results of an earlier study ${ }^{15}$ who report that majority $(80 \%)$ of their sample did not perceive pressures for dates, jokes to be sexual harassment. Similarly a South African study ${ }^{16}$ on college students found that only unwelcome touching or fondling was included in the student's definition of sexual harassment. This may also be explained in a cultural context, many of the acts labeled as sexual harassment in the Western world may not be considered as sexual harassment in Africa ${ }^{17}$.

A report ${ }^{1}$ suggests that 1 in every 2 women are likely to have experienced sexual harassment during their academic life or at work. Therefore it does not come as a surprise that more female students perceived 'a lot' of sexual harassment to be occurring at UNZA. This result is also in conformity with other research studies ${ }^{6}$ on sexual harassment which again suggests that occurrence of sexual harassment is higher in women. On questions about which category of UNZA community were likely to be involved in sexual harassment, female students perceived more harassment of students by other students and lecturer by students, whereas more male students perceived harassment of students more likely by lecturers and non-academic members of staff. An American study also reported peer sexual harassment to be common among college students ${ }^{20}$. We also found female students to be more likely to be sexually harassed, which is in order with an earlier study ${ }^{18}$ that reported $50 \%$ of female students to have been harassed by their professors or instructors. In such a case we would expect more female students to perceive lecturers harassing students.

Although the behavioural expression of sexual harassment may be culturally determined, occurrence of sexual harassment at Universities is universal ${ }^{19}$. An American study ${ }^{20}$ that included a nationwide representation of population, reported that sexual harassment is experienced by most college students and that men and women are equally likely to experience sexual harassment. But, in our study we found that more female participants to be occasionally worried of being sexually harassed, where as more male participants were rarely worried about being sexually harassed at UNZA. This is in order with studies ${ }^{3}$ which report that more female students at institutions of higher education are likely to experience sexual harassment.

Sexual harassment can be considered to be a manifestation of unequal power between men and women ${ }^{3}$. In conformity to other studies ${ }^{1,21}$, majority of our participants cited males to be the most likely perpetuators of sexual harassment. However, there have also been studies that have reported that males are frequent victims of sexual harassment. Many times women are also blamed for not reporting the sexual harassment as soon as it happens, no matter how well-respected a woman is, if she fails to report sexual harassment-or if she does report it- her status of a 'respectable woman' in the community generally suffers ${ }^{21}$. But it cannot be underestimated that sexual harassment has an impact on the individual. For example, studies have shown that consequences of sexual harassment even at low levels include impaired psychological wellbeing resulting in lowered self-esteem, nervousness, irritability and anger ${ }^{22}$. Based on this we can deduce that women in the university environment face many challenges in relation to sexual harassment.

\section{Limitations of the study}

A major challenge faced during the study was due to the sensitive nature of the topic. A number of targeted respondents did not return the questionnaires. This resulted in a lower than desired response rate. 


\section{Prevention implication}

We observe from the results of the study that sexual harassment is a problem at UNZA and the perceptions of the students suggest that female students are more likely to be affected. As sexual harassment is of serious concern in any institution, we recommend that preventive measures must be put in place at UNZA. It is up to the University to provide a safe environment for the students to learn. Our recommendations include sensitization of students on what is sexual harassment, open forums for discussion of sexual harassment, and a policy on sexual harassment. In addition to ongoing sensitization programs, a clear mechanism of complaints and regulatory procedures needs to be drawn up for both students and staff. In handling the issue of sexual harassment, the would-be offenders may sometimes be highly respected members of staff. Therefore definite measures for dealing with complaints that emphasizes on issues of confidentiality need to be put in place so that when a formal complaint is made, the complainant will have an access to redress.

\section{REFERENCES}

1. Fitzgerald, L. F. (1993). Sexual harassment in organizations. Washington, DC: American Society of Association Executives.

2. Sigal J (2006) International Sexual Harassment. Annals of New York Academy of Sciences, 1087:356369

3. Simelane, N.O (2001) Sexual Harassment: A case of the University of Natal, South Africa. Forum for African Women Educationalist.

4. Allen, D. \& Okawa, J.B. (1987). A counseling center looks at harassment. Journal of NAWDAC, 51, 9-16.

5. Fitzgerald, L.F., Shullman, S.L., Bailey, N., Richards, M., Swecker, J., Gold, Y., Ormerod, M., \& Weitzman, L. (1988). The incidence and dimensions of sexual harassment in academia and the work place. Journal of Vocational Behavior. 32, 152-175.

6. University of Zambia (2006) HIV and AIDS Policy. University of Zambia Press, Lusaka, Zambia.

7. Gervasio, A.H., \& Ruckdeschel, K. (1992). College students' judgments of verbal sexual harassment. Journal of Applied Social Psychology, 22, 190-211.
8. Yusuf, A., Senol, V.A (2006) Sexual Harassment Against Nurses in Turkey. Journal of Nursing Scholarship.39(2),200-206

9. Sandler, B.R. (1981). Sexual harassment: A hidden problem. Educational Record, 62, 52-57.

10. Adams, J.W., Kottke, J.L., and Padgitt, J.S. (1983). Sexual harassment of university students. Journal of College Student Personnel, 24, 484-90.

11. Johnson, M.P., \& Shuman, S. (1983). Sexual harassment of students at the Pennsylvania State University. Pennsylvania: Pennsylvania State University. ERIC Document Reproduction Service No. ED 250984.

12. Maihoff, N., \& Forrest, L. (1983). Sexual harassment in higher education: An assessment study. Journal of NAWDAC, 46, 3-8.

13. University of Cape Town (1992) Report on the Sexual Harassment Workshop. Cape Town.

14. Whitmore, R.L. (1983). Sexual harassment at UC Davis. Davis, CA: University of California-Davis. ERIC Document Reproduction Service No.ED 248 824.

15. Dziech, B. W,. Weiner, L. (1984). The lecherous professor. Boston: Beacon.

16. Pryor, J.B., DeSouza, Fitness, J (1997). Gender differences in the interpretation of social-sexual behavior: a cross-cultural perspective on sexual harassment. Journal of Cross-Cultural Psychology 28, 509534.

17. Tang, C., Yik, M., Cheung, F. (1995) How do Chinese college students define sexual harassment? Journal of Interpersonal Violence, 10, 503515.

18. Mayekiso, T., Bhana, K (1997). Sexual harassment: perceptions and experiences of students at the University of Transkei. South African Journal of Psychology.27, 230235.

19. Denga, D., Denga.H (2004). Sexual harassment: a student's view from a Nigerian University. The African Symposium, 4.

20. Hill, C., Silva, E. (2005). Drawing the line: Sexual harassment on campus. American Association of University Women Educational Foundation. Washington, DC.

21. Fitzgerald, L. F. (1992). Sexual harassment: Violence against Women in Workplace. American Psychologist, 48 (10):1070-1076

22. Popovich, P.M (1988). Sexual Harassment in Organizations. Employee Responsibilities and Rights Journal, 1 (4):273-282 